FILOZOFIA

Roč. 74, 2019, č. 10

DOI: https://doi.org/10.31577/filozofia.2019.74.10.4

\title{
THE FOOD THIEF: ALLEVIATION OF RESPONSIBILITY IN TERMS OF ALL-THINGS-CONSIDERED OBLIGATIONS ${ }^{1}$
}

DANIELA GLAVANIČOVÁ, Department of Logic and Methodology of Sciences, Faculty of Arts, Comenius University in Bratislava, Slovak Republic

GLAVANIČOVÁ, D.: The Food Thief: Alleviation of Responsibility in Terms of All-Things-Considered Obligations

FILOZOFIA, 74, 2019, No 10, pp. $841-851$

People sometimes have to steal food to survive. Yet it is unclear whether they are to be excused for doing so. A recent paper by Alejandra Mancilla argues for the rarely defended affirmative answer. About the same time, the Italy's Supreme Court of Cassation ruled that stealing a small amount of food when in extreme need does not constitute a crime. Given that food thieves in extreme need can be sometimes excused, the present paper aims to offer a semi-formal account of responsibility that makes space for the alleviation of responsibility in such 'food thief' scenario. I argue that a solution is buried in the notion of eligible strategy employed in an account of responsibility suggested by Matthew Braham and Martin van Hees. I argue that a possible answer to the issue of (in)eligibility can be provided in terms of all-things-considered obligations, or the lack thereof.

Keywords: All-things-considered - Eligibility - Responsibility - State of necessity

\section{Introduction}

In Genoa, in 2011, a hungry homeless man attempted to steal cheese and sausages. He was later sentenced to six months in jail and issued a $€ 100$ fine. In 2016, the Italy's Supreme Court of Cassation ruled that stealing a small amount of food when in extreme need does not constitute a crime. This decision was met with overwhelming approval in the media; it was characterised as a humane decision, an empathetic decision - the right decision.

In Kidderminster, in 2015, an equally hungry woman pled guilty to stealing a fourpack of chocolate bars. That same year, the woman was fined $£ 328.75$. The decision was met with general disapproval in the media, striking many as reminiscent of the nineteenth century, if not the medieval era. People offered help, many expressing the hope that the

\footnotetext{
${ }^{1}$ I am grateful to Carolyn Benson, Hein Duijf, Matteo Pascucci, Olivier Roy, and Marián Zouhar for their remarks and suggestions on earlier versions of this paper.
} 
judge would one day find himself in a state of poverty and starvation. They viewed the decision as a violation of human rights. A successful fundraiser was set up by a reverend.

The above cases are disturbingly real examples of what I will call the food thief scenario. In this scenario, an agent $A$ immediately needs food at the time of the theft. Moreover, $A$ has a right to food. However, $A$ cannot access food without stealing it (i.e. he or she has no money, cannot earn money at the time, has no access to free food, etc.), so $A$ actually steals food, or at least attempts to do so. Stealing is, however, forbidden.

This scenario is an instance of a broader phenomenon of doing something generally understood as forbidden in extreme need (or in the state of necessity). Given the large number of people living in extreme poverty, cases of this kind are widespread and practically important.

Mancilla $(2017,607)$ argues for the uncommon view that 'a chronically deprived agent has a right to take, use and/or occupy whatever material resources are required to guarantee her self-preservation, or the means necessary to acquire them.' The view can find some support in the abovementioned decision of Italy's Supreme Court of Cassation that stealing a small amount of food when in extreme need does not constitute a crime.

Be it as it may, the present paper does not aim to resolve this issue. Rather, given that food thieves can be (and sometimes are) excused, the paper aims to offer a semi-formal account of responsibility (understood as culpability) that makes space for this kind of alleviation of responsibility. To this end, I examine some important semi-formal and formal accounts of responsibility, asking whether these accounts lead to an appropriate analysis of responsibility in this kind of scenario.

I will argue that a satisfactory solution is buried in the very useful notion of 'eligible strategy' employed in the game-theoretic account of responsibility formulated by Matthew Braham and Martin van Hees (2012). The notion of eligible strategy is left unexplained in their account, and the reader is left to wonder about which strategies are eligible and which are not.

For sure, the general notion of (in)eligibility is broader than its normative counterpart relevant for the responsibility attribution. The notion of (in)eligibility at play is connected to the notion of excuse. The bank clerk is (generally) required to protect the bank property. However, if there is a life-threating robbery, the bank clerk is excused from this duty. Alternatively, and more controversially, the case can be modelled as constituting an exception against the general duty.

Following the above ideas, I will provide a possible answer to the issue of (in)eligibility in terms of all-things-considered obligations (or the lack thereof). The core idea here is borrowed from the literature on default logic. The insight from default logic is that one can keep simple general rules without disavowing exceptions. When the exception to the norm occurs, it conflicts with the norm. However, exceptions can block 
our use of the general norm in particular cases without being a threat to its validity and to its applicability to normal cases (e.g., if someone steals food without being in the state of necessity).

The structure of the paper is as follows. Section 1 delineates the relevant notion of responsibility and distinguishes it from other notions of responsibility. Section 2 examines semi-formal and formal accounts of responsibility and their ability to capture the food thief scenario. Section 3 argues that the abovementioned condition of eligible strategy is a promising starting point, even if it is just a placeholder for genuinely revealing answers. I provide a possible answer to the issue of (in)eligibility in terms of all-things-considered obligations. This analysis presupposes a logic that distinguishes all-things-considered oughts from so-called prima facie oughts. Section 4 concludes the paper and identifies directions for future research.

\section{Notion(s) of Responsibility}

There are many different notions of responsibility and most of them will be irrelevant for the present paper. The aim of this section is to delineate the relevant notion. To begin with, responsibility can be oriented toward the past (e.g. my having been responsible for teaching a modal logic course last year; a murderer's being responsible for killing someone) or toward the future (i.e., an agent is obliged to do something in the future; my responsibility for organising a conference next year can be listed as an example). The present focus will be on the former (retrospective or historic responsibility, as opposed to prospective responsibility). ${ }^{2}$

We can sensibly speak of being responsible for bad things (the murder case) and for neutral or even good things (being responsible for bringing cakes to the conference). My focus will be on responsibility for 'bad' things (doing something forbidden, failing to do something obligatory). Retrospective responsibility of this kind can be understood as culpability (liability or blame).

Responsibility can be individual (responsibility of an agent for his or her actions and omissions) or collective (responsibility attributed to a collective of individuals; for instance, a group of agents being responsible for the overproduction of waste). ${ }^{3}$ Importantly, there are interesting relations between the two. Arguably, in most cases collective responsibility corresponds to a class of individual responsibilities (careless consumers are collectively responsible for the overproduction of waste; each careless consumer is individually responsible). Yet there may be exceptions (e.g. a person dies in a crowded shopping mall because no single bystander takes action). Another interesting notion of

\footnotetext{
${ }^{2}$ See Cane $(2002,31)$.

${ }^{3}$ For collective responsibility and group agency, see Tamminga and Duijf (2017), Thompson (2018) and Duijf (2018).
} 
responsibility is that of vicarious responsibility (if I am responsible for a child and the child damages a hotel room, I am responsible for the damage). I will not construe vicarious responsibility as a subspecies of individual responsibility. The focus will be on individual responsibility, leaving vicarious and collective responsibility behind.

We can also speak of moral and legal responsibility (culpability, liability). These notions are substantially different, but it seems that they share the same logical form. The difference consists only in the normative source that grounds them. Note also that these notions are not disjoint (e.g. one can be both legally and morally responsible for murder). Moreover, it is less clear what an explicit permission or obligation would look like in the moral case (while there are certainly some explicitly articulated moral normative systems, e.g. the Ten Commandments, the relevant norms are not always explicitly laid out). By comparison, legal systems usually have a written form. The present focus will be primarily on legal responsibility. Occasionally, I will discuss moral responsibility.

In addition, it makes sense to distinguish between subjective and objective moral responsibility, but this seems to be less sensible in the case of legal responsibility. Objective responsibility is concerned with the question whether an agent really is responsible. In comparison, subjective responsibility is concerned with the question whether the agent feels guilty, or more generally, whether the agent is blamed from the perspective of a certain agent. ${ }^{4}$ The present focus will be on objective responsibility.

Taking all of these notions together, the paper focuses on retrospective, objective, individual responsibility, understood as culpability. Both legal and moral responsibility will be relevant. The emphasis will be put on the notion of legal responsibility.

\section{The Food Thief and Accounts of Responsibility}

Matthew Braham and Martin van Hees (2012, 605-606) suggested a promising account of retrospective moral responsibility, employing a game-theoretic framework. According to this account, three conditions must be satisfied in order to arrive at (retrospective) moral responsibility for an outcome:

(i) The agency condition: the person is an autonomous agent who performed his or her action intentionally;

(ii) The causal relevancy condition: there should be a causal relation between the agent's action and the resultant state of affairs;

(iii) The avoidance opportunity condition: the agent should have had a reasonable opportunity to have done otherwise.

\footnotetext{
${ }^{4}$ On the distinction between objective and subjective responsibility, see Lorini, Longin, and Mayor (2013).
} 
The first condition is not analysed and is presupposed to have been satisfied, allowing the authors to substantially focus on the remaining two conditions. The second condition is crucial for cases of causal overdetermination. The third condition is needed to account for alleviation of responsibility (which can be understood as excusing certain agents for doing something generally understood as forbidden or as excusing them for not doing something obligatory).

In analysing the food thief scenario, we need to make space precisely for alleviation of responsibility. It thus seems that this account possesses means for dealing with the food thief scenario. The key is buried in the condition of having a reasonable opportunity to have done otherwise. Having a reasonable opportunity to have done otherwise consists in having an eligible strategy to have done otherwise. The notion of eligible strategy is left unexplained, but the authors hint that eligible strategies can be deontic (i.e., they do not violate basic obligations). This idea will be important later on, when I will attempt to explain the notion of (in)eligibility in deontic terms.

Dyrkolbotn, Pedersen, and Broersen (2016) propose a default logic of responsibility for rule-based agents. Note that the account is designed to speak of responsibility for deriving consequences. Yet it is presupposed that agents will comply with the rules, and thus the topic is not too far from the present concern. Also, this means that the only situations where an agent can do something bad are those in which some normative conflict obtains and the element of choice is present. On this account, both food thieves would be judged to be responsible. This conclusion is not entirely welcome in the present context, for we need some means to excuse food thieves under certain circumstances. Yet if priorities or preferences are taken into account, as Dyrkolbotn, Pedersen and Broersen aim to achieve in their future work, the account may be able to deal with these scenarios in a more refined way.

Chockler and Halpern (2004) define 'degree of responsibility' and distinguish it from 'degree of blame' (blame takes into account agents' epistemic states). However, responsibility is treated as causal responsibility, and their account ignores all deontic aspects. Because of this, they cannot explain cases of responsibility alleviation based on deontic considerations (e.g. where agents can be excused because they urgently needed food and had a right to access that food, or where they can be excused because it ought to be the case that they do not starve to death). Because of this, there is no way to deal with the food thief scenario on this approach.

Lorini, Longin, and Mayor (2013) propose a STIT logic with temporal epistemic operators. They distinguish between causal and agentive responsibility on the one hand and active and passive responsibility on the other (thereby identifying four combinations). Active causal responsibility is specified as follows: agent $i$ is causally responsible for bringing about $\varphi$ iff agent $i$ sees to it that $\varphi$ is true and $\neg \varphi$ is possible. Active agentive 
responsibility is specified in the following way: agent $i$ has active agentive responsibility for $\varphi$ iff $i$ knows that her current choice makes $\varphi$ true. Moreover, they introduce the concept of guilt: an agent $i$ feels guilt iff $i$ knows that her behaviour has been in conflict with her moral standards. There is the problem that stealing or killing someone may be in conflict with our/an agent's standards, but we may still be willing to excuse the agent's stealing or killing when this was done under the pressure of other obligations. Yet it is not entirely clear how the account fares with respect to the food thief scenario, as the feeling of guilt is (admittedly) different from being guilty.

\section{Eligibility}

As mentioned above, the notion of eligibility from the 'anatomy' of responsibility suggested by Braham and van Hees was left unexplained. Despite this, authors provide useful illustrations. The core example is that of the bank clerk: The bank clerk is not held responsible for the robbery, since, as Braham and Van Hees $(2012,617)$ put it, 'her life was at risk, it would not have been appropriate to demand that she refuses to comply with the demands of the robber.' They illustrate the idea further with the difference between causing pollution by taking Sunday pleasure drives and causing the same amount of pollution by driving someone to a hospital. In general, 'a person is to be excused for the realization of some bad outcome, or does not deserve praise for a good one, if its avoidance was only feasible by the adoption of an ineligible strategy. ${ }^{5}$

Finally, they hint at deontic explanation of the term. Granted, their preferred explanation would be explicated in the game-theoretic setting. In this section, I will explore another alternative, which sits better with a multi-agent modal logic for conflicting oughts.

A reason for explication the notion in deontic terms is that the general notion of (in)eligibility is broader than its normative counterpart relevant for the responsibility attribution. For instance, my strategy to buy an ice-cream at $10 \mathrm{pm}$ is ineligible if the place closes at $9 \mathrm{pm}$. This example, however, does not open any legally or morally relevant issues (unless certain additional conditions obtain). The notion of (in)eligibility at play is connected to the notion of exception or excuse. The bank clerk is (generally) required to protect the bank property. However, if there is a dangerous, life-threating robbery, the bank clerk is excused from this duty (alternatively, this case constitutes an exception against the general duty). Similarly, stealing is (generally) prohibited. However, if the agent is starving and has no alternative means to access food, he or she can be excused from violating this prohibition. Following this idea, I will provide a possible answer to the issue of (in)eligibility in terms exceptions.

\footnotetext{
${ }^{5}$ Braham and Van Hees (2012, 618).
} 
Exceptions can be further analysed in terms of normative conflicts and all-thingsconsidered obligations. The core idea here is borrowed from the literature on default logic and defeasible reasoning (Reiter 1980). An over-used example is as follows:

(P1) All birds can fly.

(P2) Tweety is a bird.

Therefore,

(C) Tweety can fly.

However, it can happen that Tweety has a broken wing, or that Tweety is a penguin, or that Tweety is an ostrich, and so forth. In either of these cases, Tweety cannot fly. Of course, one can opt for a 'classical way' and incorporate all exceptions directly into rules. For instance, we can have it that all birds can fly, except for birds with broken wings, penguins, ostriches, and so forth. Applying this strategy, the internal consistency of the 'knowledge base' would be preserved. However, it may not be easy to list all exceptions; rules or general claims would be more complex; and they could be very repetitive if the same exception pertains to many general rules. The insight from default logic is that one can do both: one can keep simple general rules and one can acknowledge exceptions. Exceptions can block our use of the general rules in particular cases without invalidating these rules.

Similarly, one can opt for a classical way and incorporate all exceptions directly into rules (or norms) in the legal or moral case. Applying this strategy, normative conflicts could be largely avoided (internal consistency of normative systems would be preserved). Naturally, this would be a pleasant consequence. However, there are often too many exceptions, and it would be neither parsimonious, nor elegant, and maybe not even possible to do the manoeuvre. Repetition would result when the same exception pertains to many different rules (what is clearly the case with the state of necessity). Also, each rule would be analysed as being much more complicated than it really is in legal texts, and in would be analysed as much more complicated than it could be in an alternative defeasible approach. Also, we may not be able to anticipate all exceptions that a rule can have. Furthermore, these rule with explicit exceptions can lead to a more frequent (mis)using of these exceptions, what is clearly undesired even by a defendant of right of necessity. As Mancilla $(2017,609)$ puts it, 'we should think of the right of necessity as a legitimate last resort for those in need while fairer and more equitable mechanisms of wealth redistribution at the domestic and global levels are not in place.' The alternative option is to keep simple norms along with exceptions. When the exception to the norm occurs, it conflicts with the norm: 
Exceptions can block our use of the general norm in particular cases without being a threat to its validity and to its applicability to normal cases (e.g., if someone steals food without being in the state of necessity).

In the scenario under examination, the option of not stealing can be seen as ineligible (the starving agent has no other means to access food - stealing is the last resort). The right to food can be understood as generating an exception (and like it or not, a permission of a certain, very weak kind). Note that the question of whether this particular path of responsibility alleviation is persuasive is not important for present purposes. What is relevant is that such alleviation is possible. For this reason, we need to make space for this alleviation in the analysis of responsibility.

A provisional reconstruction of the scenario along the lines suggested above runs as follows. Stealing is generally forbidden for any agent, so it is forbidden also for an agent $a$ from the food thief scenario (formally, $O_{a} \neg \varphi$ ). However, needy, starving agents can be sometimes excused for doing so, and thereby, in these circumstances their (normally forbidden) course of action ceases to be forbidden for the agent (formally, $\neg O_{a} \neg \varphi$ ).

Of course, one wants to avoid deriving a contradiction, i.e., a formula stating that $O_{a} \neg \varphi \wedge \neg O_{a} \neg \varphi$ holds. In addition, the situation surely would not be reconstructed as involving a contradiction by the judge. Similarly, one would not say that our knowledge base related to birds and their ability to fly is inconsistent. Despite this, the above example of default reasoning can be a plausible and useful analysis of our talk about exceptions. In a similar vein, the above suggestion can be a plausible and useful analysis of the food thief scenario (and more generally, of exceptions in the legal or moral domain). This is so because the contradiction is not the final result of the analysis. Default logic backtracks a derivation when the contradiction is derived. Similarly, we need to backtrack the derivation of $O_{a} \neg \varphi$ whenever an exception $\neg O_{a} \neg \varphi$ is derived.

Formally, there are many ways how to employ this strategy in deontic logic. ${ }^{6}$ Reasoning on a preferential basis is often employed. ${ }^{7}$ However, the search for the best conflict-tolerant deontic logic would take us far beyond our present concerns. For the ease of explanation, I will focus merely on the branch of deontic logics for normative conflicts which distinguishes prima facie from all-things-considered obligations, prohibitions, or permissions. ${ }^{8}$ In terms of oughts, prima facie ought is understood as a real obligation, which, however, may not be agent's final obligation. Prima facie

\footnotetext{
${ }^{6}$ For the evidence, see Goble (2013).

${ }^{7}$ See Sartor (1992).

${ }^{8}$ Goble $(2013,256-296)$.
} 
oughts can conflict. All-things-considered ought is construed as an agent's final obligation. The prevailing view is that all-things-considered oughts cannot conflict. This distinction is particularly apt for the present purposes, or so I will attempt to show below.

Read $O_{a}^{p f} \varphi$ as $\varphi$ is prima facie obligatory for $a$ and $O_{a}^{a t c} \varphi$ as $\varphi$ is all-thingsconsidered obligatory for $a$. A necessary condition for responsibility (culpability) for $\varphi$ (which is forbidden by one normative system) would then be that $\varphi$ is, all things considered, forbidden for the given agent (formally, $O_{a}^{a t c} \neg \varphi$ ). In other words, a person is responsible for doing something forbidden only if there is no conflicting ought or permission of higher importance.

Going back to the food thief scenario, and thinking of normative sources in a very broad way, stealing has been prima facie forbidden by one normative source. In addition, stealing has been prima facie permitted by another normative source (the right to food or the state of necessity norm). If the right to food is to be preferred over the prohibition of stealing, then stealing will not be all-things-considered forbidden for the given agent and consequently, the food thief will not be guilty of committing a crime. Opposite preferences will lead to the opposite responsibility judgement. Stealing will be all-things-considered forbidden, and the food thief will be culpable.

In this way, the notion of eligibility has lead us to the notion of exception. The notion of exception was analysed in terms of conflicts among norms and all-thingsconsidered obligation: if a strategy, an action, or a proposition is eligible, the situation lacks normative conflict of a certain kind. Subsequently, the prima facie versus allthings-considered distinction has been employed as one of many available tools of conflict-tolerant deontic logics.

Finally, let me now to reformulate the conditions for responsibility proposed by Braham and van Hees in the light of analysis provided in this section. I will keep the first two conditions, amend the third condition, and add the fourth condition. The subsequent tentative definition of responsibility is as follows:

(i) The agency condition: the person is an autonomous agent who performed his or her action intentionally;

(ii) The causal relevancy condition: there should be a causal relation between the agent's action and the resultant state of affairs;

(iii) The avoidance opportunity condition: the agent should have had an opportunity to have done otherwise;

(iv) The normative eligibility condition: doing otherwise was an all-thingsconsidered obligation for the agent. 
The food thief scenario meets the first three conditions. However, it is questionable whether the last condition is met. The Italy's Supreme Court of Cassation can be seen as arguing for the negative answer (taking my explanation of the manoeuvre borrowed from default logic on board: the talk about exceptions is analysed as the talk about normative conflicts and all-things-considered oughts). In the case from Kidderminster, the fourth condition was seen as being satisfied. Be it as it may, the analysis makes space for different answers and thereby makes space both for alleviation of responsibility, as well as for attribution of responsibility.

\section{Conclusions and Future Work}

The present paper has focused on the so-called food thief scenario and the corresponding notion of responsibility. The paper examined semi-formal and formal accounts of responsibility and their ability to analyse the scenario in question (and the relevant notion of responsibility) appropriately. It was argued that an (unexplained) notion of eligible strategy employed by Braham and van Hees can offer a solution to the problem. The present paper provided a possible answer to the issue of eligibility in terms of all-thingsconsidered obligations. Consequently, the analysis requires a logic of responsibility which is able to acknowledge and deal with the distinction between prima facie and allthings-considered obligations. ${ }^{9}$ Standardly, this requires a conflict tolerant logic and reasoning on preferential basis: which prima facie oughts are to be elevated to the status of all-things considered oughts? Related to these two issues, an important task for future research is to find the most convenient conflict tolerant logic of responsibility. Another task for future research is to find a mechanism for preferential reasoning (over normative sources) which is appropriate for the analysis of responsibility attribution.

On the basis of my semi-formal analysis of the food thief scenario, I reformulated the definition of responsibility proposed by Braham and van Hees to make space for the alleviation of responsibility when there is no all-things-considered obligation to do otherwise. I do not claim that this putative definition of individual historic responsibility understood as culpability overcomes all difficulties pertaining to this notion. However, if the analysis presented in the present paper is acceptable, the fourth condition of individual historic responsibility provides a small step further in the explanation of this extremely difficult but practically very important notion.

\section{Bibliography}

BRAHAM, M., VAN HEES, M. (2012): An Anatomy of Moral Responsibility. Mind, 121 (483), 601 - 634. DOI: https://doi.org/10.1093/mind/fzs081

CANE, P. (2002): Responsibility in Law and Morality. Oxford and Portland: Hart Publishing.

\footnotetext{
${ }^{9}$ Some results in this direction are provided in Glavaničová and Pascucci (2019).
} 
DUIJF, H. (2018): Let's Do It! Collective Responsibility, Joint Action, and Participation. (Dissertation, University of Utrecht).

DYRKOLBOTN, S., PEDERSEN, T., BROERSEN, J. (2016): Arguments, Responsibilities and Moral Dilemmas in Abductive Default Logic. In: Roy, O., et al. (eds.): Deontic Logic and Normative Systems: 13th International Conference DEON 2016. Milton Keynes: College Publications, $64-79$.

GLAVANIČOVÁ, D., PASCUCCI, M. (2019): Formal Analysis of Responsibility Attribution in a Multimodal Framework. In: Baldoni M., et al. (eds.): PRIMA 2019: Principles and Practice of Multi-Agent Systems. PRIMA 2019. Lecture Notes in Computer Science, vol 11873. Cham: Springer, 36-51. DOI: https://doi.org/10.1007/978-3-030-33792-6_3

GOBLE, L. (2013): Prima Facie Norms, Normative Conflicts, and Dilemmas. In: Gabbay, D. M., et al. (eds.): Handbook of deontic logic and normative systems. Milton Keynes: College publications, $241-351$.

CHOCKLER, H., HALPERN, J. Y. (2004): Responsibility and Blame: A Structural-Model Approach. Journal of Artificial Intelligence Research, 22, 93 - 115.

LORINI, E., LONGIN, D., MAYOR, E. (2013): A logical analysis of responsibility attribution: emotions, individuals and collectives. Journal of Logic and Computation, 24 (6), 1313 - 1339. DOI: https://doi.org/10.1093/logcom/ext072

MANCILLA, A. (2017): What the Old Right of Necessity Can Do for the Contemporary Global Poor. Journal of Applied Philosophy, 34 (5), 607 - 620. DOI: https://doi.org/10.1111/ japp. 12170

REITER, R. (1980): A logic for default reasoning. Artificial intelligence, 13 (1 - 2), 81 - 132. DOI: https://doi.org/10.1016/0004-3702(80)90014-4

SARTOR, G. (1992): Normative conflicts in legal reasoning. Artificial intelligence and law, 1 (2 3), 209 - 235. DOI: https://doi.org/10.1007/BF00114921

TAMMINGA, A., DUIJF, H. (2017): Collective obligations, group plans and individual actions. Economics \& Philosophy, 33 (2), 187 - 214. DOI: https://doi.org/10.1017/ S0266267116000213

THOMPSON, C. (2018): The Moral Agency of Group Agents. Erkenntnis, 83 (3), 517 - 538. DOI: https://doi.org/10.1007/s10670-017-9901-7

This work was supported by the Slovak Research and Development Agency under the contract no. APVV-17-0057 and by the grant no. UK/414/2018.

Daniela Glavaničová

Department of Logic and Methodology of Sciences

Faculty of Arts

Comenius University in Bratislava

Gondova 2

81499 Bratislava

Slovak Republic

e-mail: daniela.glavanicova@gmail.com

ORCID ID: https://orcid.org/0000-0002-4189-9281 